\title{
Elderly Mortality in Denmark: Past, Present and Future
}

\author{
GRAHAM W. LEESON
}

The demography of the elderly

Increasing proportions of each generation are now attaining old age in Denmark. Of those born in $1900-19,55$ percent survived to age $60-79$ in 1980 , whereas only 44 percent of those born in 1880-99 survived to this age in 1960 . The same is true of the extreme aged in 1960 and 1980 where the survival ratios have been 10 percent ( $1880-99$ generation) and 6 percent ( $1860-79$ generation). Not only this, but the generation sizes have played a part in the numerical increase in the number of elderly. The 55 percent surviving to age $60-79$ in 1980 were born in a period when the annual number of live births was approximately 77,000 , whereas the 44 percent surviving to this age in 1960 were born when the annual number of live births was approximately 71,000 .

In 1940, there were 456,000 elderly in Denmark. By 1983, they numbered 1.02 million, and their proportion of the total population increased from almost 12 percent to 20 percent. Furthermore, the elderly dependency burden ${ }^{1}$ grew from 21.4 in 1940 to 38.1 in 1983.

The elderly population has also aged. In 1940 , only 9 percent of them were aged 80 and over. Today, the figure is 15.2 percent.

As well as these changes in the age distribution of the elderly, an increasing proportion of elderly are females. In 1940, there were 90 males for every 100 females. Today, there are only 76 males for every 100 females.

As is well known among demographers, at least, an aging population is the consequence of declining fertility and declining mortality. During the first half of the century, declining fertility was the dominant factor. At the turn of the century, the fertility level in Denmark was at more than 4.4 live births per female, but by the 1950 s it stood at approximately 2.6 , and today it is less than 1.40 . In that same period, mortality declined to counteract declining fertility in as much as it was concentrated in the younger age groups. In later years, mortality declines benefited all age groups, thereby resulting in a larger elderly population.

\section{Mortality development}

The last 20 years or so have witnessed an unprecedented decline in elderly mortality, especially for females and especially for the extreme aged ( 80 years and over). Whereas all females over the age of 60 have experienced declines, only males aged 75 and over have had a similar experience, though on a more modest scale.

As can be seen from Table 1, the life expectancy at age 60 for Danish females rose from 16.3 to 19.0 in the period from $1901-05$ to $1956-60$. In the subsequent

1 The number of elderly (60 and over) per 100 persons $20-59$ (the work force). 
$20-25$ years, this rose again by the same numerical amount to 21.6 . In contrast, male life expectancies in 1981-82 had fallen slightly compared with the 1956-60 figure, having increased from 15 years at the turn of the century to 17.3 by the end of the $1960 \mathrm{~s}$. Thus, while female life expectancy at age 60 was $8-10$ percent higher than males in 1901-05 and 1956-60, by 1981-82 it was 26 percent higher. The extreme aged of both sexes have benefited substantially, but again more so in the case of females. Male life expectancies increased by almost the same since $1956-60$ as they did from $1901-05$ to $1956-60$ ( 0.5 versus 0.8$)$, whereas for females, the increase in the last $20-25$ years ( 1.8 years) is three times as great as in the first 60 years of the century. Here, again, the difference in favor of females has increased from 5-10 percent to 25 percent.

$\mathrm{T}$ a b l e 1. Average expectations of life at ages 60 and 80 in 1901-05, 1956-60 and 1981-82.

\begin{tabular}{lrrrrrrr}
\hline & \multicolumn{3}{c}{ Males } & & \multicolumn{3}{c}{ Females } \\
\cline { 2 - 3 } \cline { 6 - 7 } Age & $1901-05$ & $1956-60$ & $1981-82$ & & $1901-05$ & $1956-60$ & $1981-82$ \\
\hline 60 & 15.0 & 17.3 & 17.1 & & 16.3 & 19.0 & 21.6 \\
80 & 5.0 & 5.8 & 6.3 & & 5.5 & 6.1 & 7.9 \\
\hline
\end{tabular}

In Figure 1 (see p. 159), probabilities of death at single years of age over 60 for males and females in 1978-79 and 1981-82 are graphed as percentages of the probabilities in 1956-60. The pronounced sex differences in development can be clearly seen, as can the declines in favor of the extreme aged. As far as males are concerned, in 1978-79 there was a clear difference between the development for those aged 60-75 and those aged over 75. The younger males had experienced increases of up to 13 percent compared with the level in 1956-60, while the mortality level of older males had decreased by up to 20 percent. By 1981-82, the level for the younger group had fallen to between 95 and 105 percent of the level in 1956-60. Mortality experience for elderly females compared with that in 195660 is almost unchanged from $1978-79$ to $1981-82$. It can be seen that the decline benefits all age groups, the largest observed decline at around age $75-80$ ( 35 percent decline). The female decline is substantially greater than that of males at all but the very highest ages.

- Sex differences in mortality :-

Excess male mortality among the elderly has also increased appreciably since 1956-60, as can be seen from Figure 2 (see p. 160). In 1956-60, excess male mortality ranged from 50 percent (age 63) to just 2 percent (age 68), but by $1981-82$ it ranged from 99 percent (age 71) to 18 percent (aged 90 and over). It can be seen that excess male mortality decreases with increasing age, starting at around age 70. In recent years the age-specific decrease in excess has been much more pronounced in comparison to $1956-60$.

\section{Causes of death}

To facilitate a reasonable consideration of the contribution of the development in different causes of death to the overall mortality development among the elderly, causes of death have been grouped into 9 main groups as shown in Tables $2 \mathrm{~A}$ and $2 \mathrm{~B}$ (pp. 162-163). This approach has obvious limitations, but is deemed adequate for a summary of causes of death. 
F i g u r e 1. Development in elderly mortality $(1956-60=100)$ in Denmark

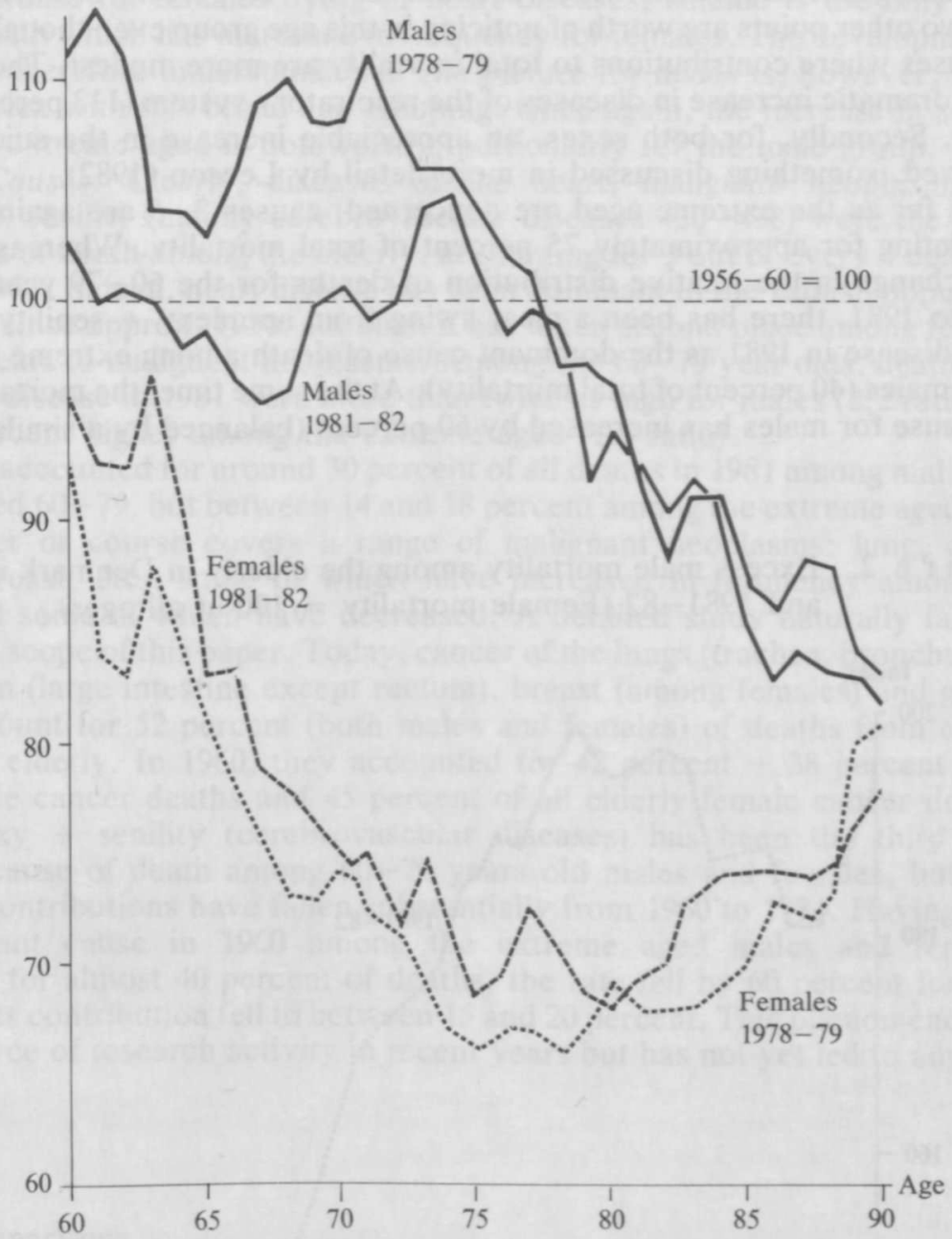

In Tables 2A-2B, death rates (cause-specific) are shown in 1960 and 1981 for males and females separately and for the two broad groups $60-79$ and $80+$, thereby distinguishing between aged and extreme aged. Also shown in the tables are the percentage changes in the death rates in the period covered.

It is not sufficient to consider percentage changes alone without some knowledge of the contribution of each cause of death to the total mortality. This is shown in Table 3 (see p. 163).

Let us now consider the age group 60-79 years. Excluding "All other causes", the main groups are 3,4 and 5 which contribute collectively 77.5 percent of deaths in this age group among males in 1960 and 77 percent in 1981. Among females, these causes contribute 77 and 75 percent in 1960 and 1981 respectively. Diseases of the heart (5) is the largest single contributor for both sexes, closely followed in 1981 for females by malignant neoplasms. It is among these groups we would expect to find the trends in total mortality.

And this is seen to be true. Only apoplexy and senility has the same direction of change for both sexes and whereas male heart disease mortality shows a modest increase of 6 percent, female mortality from this cause has decreased by as much as 26 percent. The tendency towards increased male mortality in this 
group (see Fig. 1) would seem to lie with quite substantial increases in mortality from malignant neoplasms which account for 24-28 percent of all deaths.

Two other points are worth of noticing in this age group even though they refer to causes where contributions to total mortality are more modest. The first point is the dramatic increase in diseases of the respiratory system (113 percent) among males. Secondly, for both sexes, an appreciable increase in the suicide rate is observed, something discussed in more detail by Leeson (1982).

As far as the extreme aged are concerned, causes 3-5 are again dominant, accounting for approximately 75 percent of total mortality. Whereas there was little change in the relative distribution of deaths for the 60-79 year olds from 1960 to 1981, there has been a clear swing from apoplexy + senility in 1960 to heart disease in 1981 as the dominant cause of death among extreme aged males and females ( 40 percent of total mortality). At the same time, the mortality rate for this cause for males has increased by 60 percent (balanced by a similar decrease

F i g u r e 2. Excess male mortality among the elderly in Denmark in 1956-60 and 1981-82 (Female mortality $=100$ at all ages).




in apoplexy + senility), but by only 9 percent for females. Apart from this modest increase for females dying of heart diseases, suicide is the only other cause of death which has increased in frequency for females. The development in Figure 1 is therefore understandable. The picture for males is, however, rather more complex with this broad age grouping. Once again, the increase in suicide among the extreme aged is noteworthy, particularly for the male group.

Main Causes: Clearly, diseases of the heart, malignant neoplasms and apoplexy + senility (mainly cerebrovascular diseases $430-438$ ) were the dominant causes of death among the elderly, accounting for 3 out of every 4 deaths in 1960 and 1981. Indeed, heart disease has been dominant in the Danish population as a whole since approx. 1950, although it has taken second place among females in recent years to malignant neoplasms. Among the 60-79 year olds, death rates from heart disease in 1981 were more than twice as high for males ( 2.2 ratio) but only 30 percent higher among the extreme aged (1.3 ratio).

Cancer accounted for around 30 percent of all deaths in 1981 among males and females aged $60-79$, but between 14 and 18 percent among the extreme aged. The term cancer of course covers a range of malignant neoplasms: lung, colon, genitals, breast, etc., some of which have increased in frequency among the elderly and some of which have decreased. A detailed study naturally falls far beyond the scope of this paper. Today, cancer of the lungs (trachea, bronchus and lung), colon (large intestine except rectum), breast (among females) and genital organs account for 52 percent (both males and females) of deaths from cancer among the elderly. In 1960 , they accounted for 42 percent -38 percent of all elderly male cancer deaths and 45 percent of all elderly female cancer deaths.

Apoplexy + senility (cerebrovascular diseases) has been the third most dominant cause of death among 60-79 years old males and females, but both rates and contributions have fallen substantially from 1960 to 1981 . Having been the dominant cause in 1960 among the extreme aged males and females, accounting for almost 40 percent of deaths, the rate fell by 60 percent for both sexes and its contribution fell to between 15 and 20 percent. This phenomenon has been a source of research activity in recent years but has not yet led to any final results.

\section{Nordic comparisons}

The mortality experience of the elderly in Denmark in the last 20-25 years has not been unique. Recent reports from the United States (Rosenwaike et al, 1980) suggest similar results if less pronounced developments, especially for the extreme aged ( 85 and over in that study) who from 1966 to 1977 experienced declines of over 25 percent in their mortality level. Male mortality increases among the younger elderly have also been registered in other European countries in the period after 1960 (Caselli and Eigidi, 1979). Notably in Belgium (8 percent increase), Norway ( 8 percent) and The Netherlands (18 percent), but only Belgium and Norway can present mortality declines after age 75 for males.

In Figure 3, graphs similar to Figure 1 for Denmark are shown for the other Nordic countries. The development for the elderly in Iceland seems to be have been rather erratic, but a level in 1977-78 below that of 1951-60 seems to be the overall impression, with the largest female decreases exceeding those in the other countries. Female experience especially would appear to be uniform with decreases of between 20 and 40 percent above age 60 . The male declines are at all ages substantially lower than the female.

Though not entirely a Nordic phenomenon, the elderly mortality decline outlined above has at least been registered in more or less the same form, to the same extent in all five member states. 
$\mathrm{T}$ a b 1 e 2 A. Elderly death rates per 100,000 according to age, sex and cause ${ }^{1}$, 1960 and 1981

A. $60-79$ years

\begin{tabular}{|c|c|c|c|c|c|c|c|}
\hline \multicolumn{2}{|l|}{ Cause } & \multicolumn{3}{|c|}{ Males } & \multicolumn{3}{|c|}{ Females } \\
\hline . & & 1960 & 1981 & $\begin{array}{c}\% \\
\text { Change }\end{array}$ & 1960 & 1981 & $\begin{array}{c}\% \\
\text { Change }\end{array}$ \\
\hline 1. Tuberculosis: & $010-019$ & 22 & 9 & -59 & 7 & 3 & -57 \\
\hline $\begin{array}{l}\text { 2. Infectious } \\
\text { diseases }\end{array}$ & $\begin{array}{l}000-009 \\
020-136\end{array}$ & 17 & 6 & -65 & 12 & 5 & -58 \\
\hline $\begin{array}{l}\text { 3. Malignant } \\
\text { neoplasms }\end{array}$ & $140-209$ & 936 & 1177 & +26 & 766 & 742 & -3 \\
\hline $\begin{array}{l}\text { 4. Apoplexy and } \\
\text { senility }\end{array}$ & $\begin{array}{l}290,430-438 \\
440,441,794\end{array}$ & 533 & 392 & -26 & 516 & 274 & -47 \\
\hline $\begin{array}{l}\text { 5. Diseases of } \\
\text { the heart }\end{array}$ & $390-429$ & 1556 & 1650 & +6 & 1007 & 745 & -26 \\
\hline $\begin{array}{l}\text { 6. Diseases of the } \\
\text { respiratory } \\
\text { system }\end{array}$ & $460-519$ & 155 & 331 & +113 & 111 & 140 & -26 \\
\hline 7. Accidents & $\begin{array}{l}800-949 \\
960-999\end{array}$ & 119 & 68 & -43 & 84 & 50 & -40 \\
\hline 8. Suicide & $950-959$ & 51 & 69 & +35 & 27 & 36 & +33 \\
\hline $\begin{array}{l}\text { 9. All other } \\
\text { causes }\end{array}$ & & 512 & 486 & -5 & 452 & 346 & -23 \\
\hline Total & & 3902 & 4188 & -7 & 2982 & 2341 & -21 \\
\hline
\end{tabular}

1 The causes of death are grouped into 9 main groups covering the numbers shown in the international Detailed List No. 8 (revised).

Source: Computed from figures published in Causes of Death in Denmark 1960 and 1981, published by the National Board of Health, Copenhagen.

\section{Projections}

Projections of the age and sex distribution of the Danish population are carried out by Danmarks Statistik who no longer operate with alternative developments in mortality. Projections are based on a continuation of the observed values in the latest life tables, so that no attempt is made to introduce development in mortality into the projections. In the case of fertility, the total fertility rate for the most recently available calendar year (and the underlying age-specific fertility rates) is assumed either to remain active throughout the projection period or to increase over a 10 year period before stabilizing.

Mortality declines among the elderly have been much more pronounced in recent years than anticipated, and this has produced substantially more elderly people than predicted (Leeson, 1981). It seems relevant, therefore, that future population projections at least make a token attempt to reflect this development. This has been done by Leeson (1980) in co-operation with the Danish Government Commission on Aging.

Accurate assumptions of mortality development are crucial to plan effectively for the needs of the elderly. To illustrate the consequences of varying assump- 
$\mathrm{T}$ a b l e 2B. Elderly death rates per 100,000 according to age, sex and cause ${ }^{1}$, 1960 and 1981.

B. 80 years and over

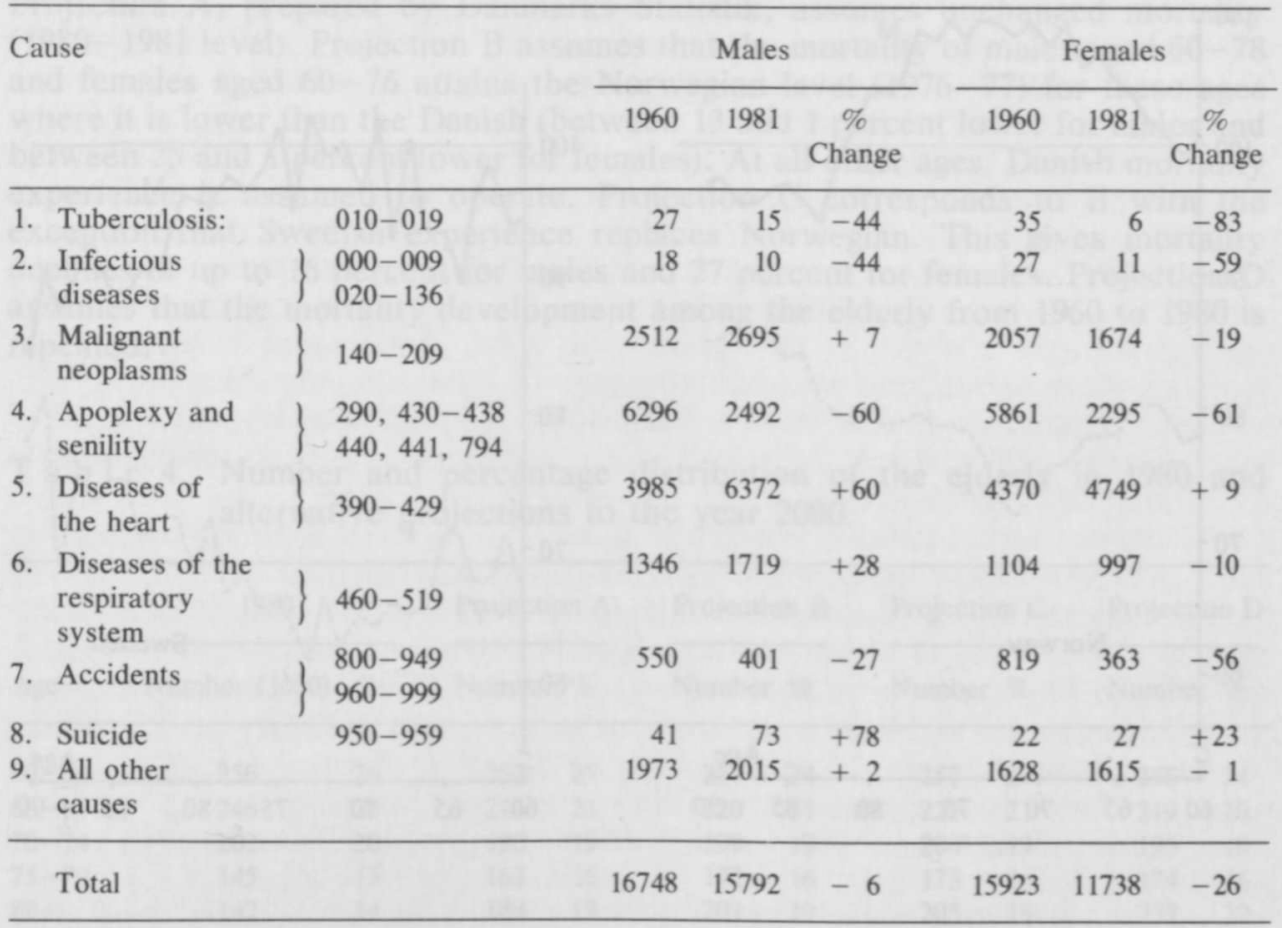

1 The causes of death are grouped into 9 main groups covering the numbers shown in the International Detailed List No. 8 (revised).

Source: Computed from figures published in Causes of Death in Denmark 1960 and 1981, published by the National Board of Health, Copenhagen.

$\mathrm{T}$ a b l e 3. Relative distribution of deaths among the elderly according to cause and sex and age, 1960 and 1981.

\begin{tabular}{|c|c|c|c|c|c|c|c|c|}
\hline \multirow[b]{3}{*}{ Cause } & \multicolumn{4}{|c|}{$60-79$ years } & \multicolumn{4}{|c|}{80 years and over } \\
\hline & \multicolumn{2}{|c|}{ Males } & \multicolumn{2}{|c|}{ Females } & \multicolumn{2}{|c|}{ Males } & \multicolumn{2}{|c|}{ Females } \\
\hline & 1960 & 1981 & 1960 & 1981 & 1960 & 1981 & 1960 & 1981 \\
\hline 1. Tuberculosis & 6 & 2 & 2 & 1 & 2 & 1 & 2 & $<1$ \\
\hline 2. Inf. diseases & 4 & 1 & 4 & 2 & 1 & 1 & 3 & 1 \\
\hline 3. Mal. neoplasms & 240 & 281 & 257 & 317 & 150 & 171 & 129 & 143 \\
\hline 4. Apo. and senility & 136 & 94 & 173 & 117 & 376 & 158 & 368 & 196 \\
\hline 5. Heart disease & 399 & 394 & 338 & 318 & 238 & 403 & 274 & 404 \\
\hline 6. Resp. system & 40 & 79 & 37 & 60 & 80 & 109 & 69 & 85 \\
\hline 7. Accidents & 30 & 16 & 28 & 22 & 33 & 25 & 51 & 31 \\
\hline 8. Suicide & 13 & 17 & 9 & 15 & 2 & 5 & 2 & 2 \\
\hline 9. All others & 132 & 116 & 152 & 148 & 118 & 127 & 102 & 138 \\
\hline Total & 1000 & 1000 & 1000 & 1000 & 1000 & 1000 & 1000 & 1000 \\
\hline
\end{tabular}


F i g u r e 3. Elderly mortality in Norway, Sweden, Finland and Iceland from $1956-60$ to $1978-79^{a}$. $(1956-60=100)$.
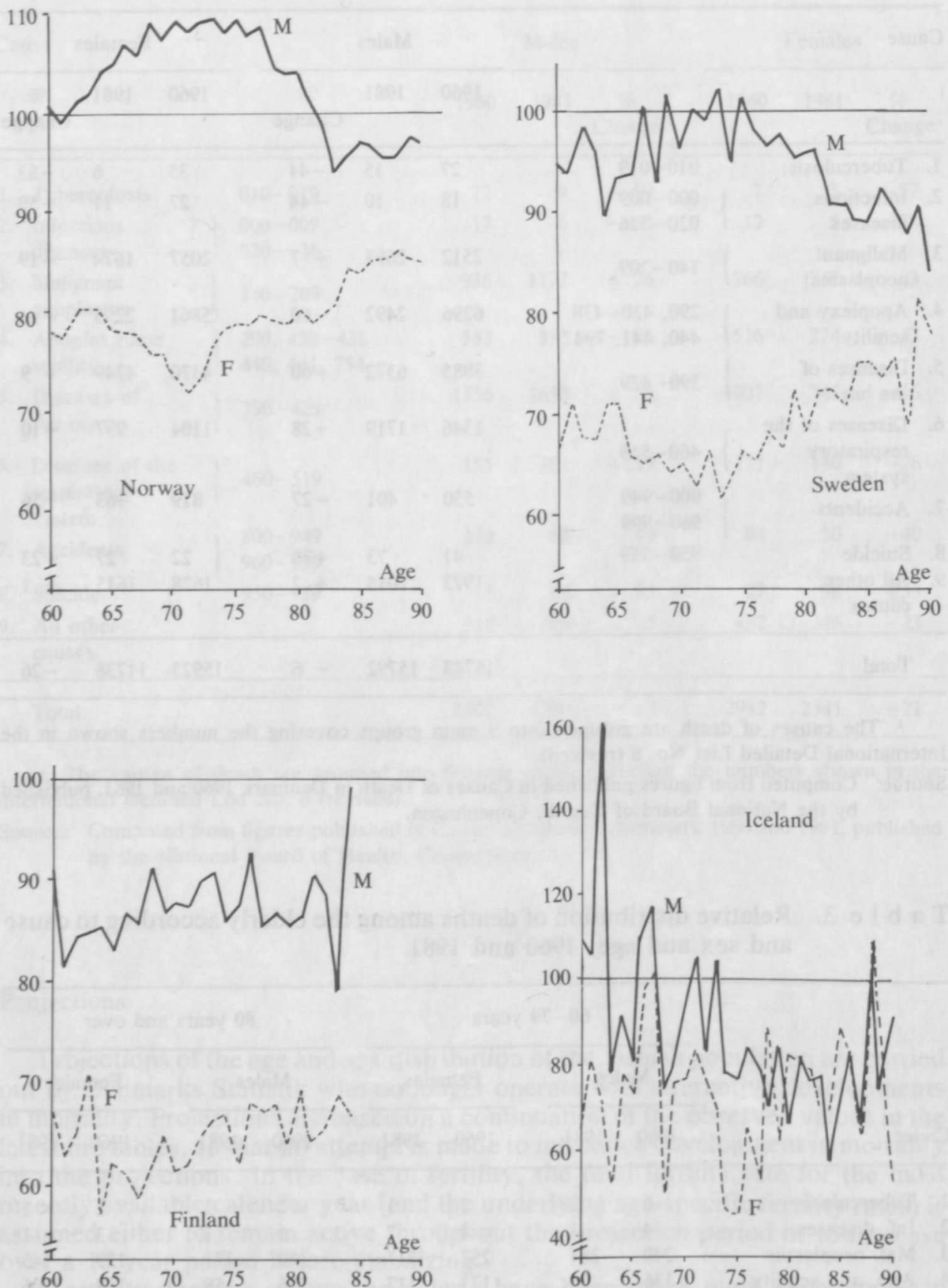

a. For Iceland, the base year is $1951-60(=100)$ and the development is to $1977-78$. Source: Matthiessen and Leeson (1983). 
tions of mortality development on the projections of the elderly, four sets of projections of the population aged 60 and over in the year 2000 are shown in Table 4. Each set varies only in its assumption of mortality development. Projection A, prepared by Danmarks Statistik, assumes unchanged mortality (1980 - 1981 level). Projection B assumes that the mortality of males aged 60-78 and females aged 60-76 attains the Norwegian level (1976-77) for these ages where it is lower than the Danish (between 13 and 1 percent lower for males and between 25 and 1 percent lower for females). At all other ages, Danish mortality experience is assumed to operate. Projection C corresponds to B with the exception that Swedish experience replaces Norwegian. This gives mortality declines of up to 16 percent for males and 27 percent for females. Projection D assumes that the mortality development among the elderly from 1960 to 1980 is repeated.

$\mathrm{T}$ a b l e 4. Number and percentage distribution of the elderly in 1980 and alternative projections to the year 2000 .

\begin{tabular}{|c|c|c|c|c|c|c|c|c|c|c|}
\hline \multirow[b]{2}{*}{ Age } & \multicolumn{2}{|l|}{1980} & \multicolumn{2}{|c|}{ Projection A } & \multicolumn{2}{|c|}{ Projection B } & \multicolumn{2}{|c|}{ Projection C } & \multicolumn{2}{|c|}{ Projection D } \\
\hline & Number $(1000)$ & $\%$ & Number & $\%$ & Number & $\%$ & Number & $\%$ & Number & $\%$ \\
\hline $60-64$ & 256 & 26 & 252 & 25 & 257 & 24 & 257 & 24 & 256 & 24 \\
\hline $65-69$ & 246 & 25 & 214 & 21 & 220 & 21 & 221 & 21 & 219 & 20 \\
\hline $70-74$ & 202 & 20 & 190 & 19 & 199 & 19 & 200 & 19 & 196 & 18 \\
\hline $75-79$ & 145 & 15 & 163 & 16 & 172 & 16 & 173 & 16 & 174 & 16 \\
\hline $80+$ & 142 & 14 & 189 & 19 & 201 & 19 & 205 & 19 & 237 & 22 \\
\hline Total & 991 & 100 & 1008 & 100 & 1049 & 100 & 1056 & 100 & 1082 & 100 \\
\hline
\end{tabular}

Sources: Projection A: Statistiske Efterretninger 15, pp. 22-43, 1983. (Danmarks Statistik) Projection B, C, D: Leeson (1980)

With just 4 alternatives, there is a suggestion of a wide range of growth of the elderly population, with variations from the official projections to the year 2000 being especially noticeable among the extreme aged ( 80 years and over). From 1980 to 2000 , the elderly population may increase by as little as 1.7 percent or as much as 9.2 percent (projections A and D respectively). As mentioned, growth of the extreme aged population will be most dramatic, this age group's increase ranges from 33.1 percent (A) to 67 percent (D), and will account for approximately 20 percent of the elderly population.

\section{Discussion}

By the end of this century, there is little doubt that the number and age distribution of the elderly will have changed sufficiently to warrant a closer look at some of the potential consequences of aging for the elderly and for the general population.

Societal impacts of aging (including the aging of the elderly themselves) depend largely on the future health of the elderly. As an example, if the use of nursing homes remains constant, the number of elderly nursing home residents would increase from 46,500 in 1980 to 62,500 according to Projection A and 73,500 
according to Projection D by the year 2000. Of these, 72 and 76 percent respectively would be aged over 80 compared with 64 percent today. On the other hand, if the health of the elderly improves or alternative forms of care and treatment are developed, the number may be reduced. Whatever happens, the extreme aged will demand the most resources: both medical, social and financial. The needs of geriatric patients can only be met if staff are aware of these needs from a point of view of medical and a social services.

Of course, the health of the elderly may improve so that morbidity and the use of health services decreases. Indeed, factors which have led to the declines in mortality among the elderly experienced in recent years may also lead to changes in morbidity and patterns of health care. Perhaps, modern populations are approaching a state devoid of premature death with the emergence of natural death at the end of a natural life span (Fries, 1980). Attainment of such a state demands the posponement of debilitating chronic illness via changing life styles, and such population models must include significant increases in the human life span (Leeson, 1984), Keyfitz, 1978) or a rectangularization of the survival surve within the existing life span.

As excess male mortality continues to increase and the difference between male and female life expectancies likewise, the elderly females will become increasingly the focus of attention. In 1980 in Denmark, 49 percent of females aged 60-79 and only 13 percent of those aged 80 and over were married compared with 76 and 49 percent for males. Indeed, 14 percent of the over 80 females have never been married and have no extended family (Leeson and Matthiessen, 1982).

Social Security systems relate strongly to the aging of a population, especially as the trend is for the elderly to live longer and retire earlier. A possible restructuring of the system may need to be contemplated, with a return to higher retirement ages.

Society will of course accomodate the increases in the elderly population. Just as they created the need for more schools, more jobs, and more housing, the baby-boom generation will create the need for more geriatric services as they age and become the well-educated, perhaps wealthy elderly of the year 2000 .

\section{References}

Caselli, G. and Eigidi, V. (1979). New trends in European mortality. Council of Europe, ED-MM (79), 1, provisional, Strasbourg.

Fries, J. F. (1980). Ageing, natural death and the compression of morbidity. N. Engl. J. Med. 303 (3): $130-135$.

Keyfitz, N. (1978). Improving life expectency. An uphill road ahead. Am. J. Pub. Health 68 (10): 954-956.

Leeson, G. W. (1980). Nogle beregninger vedr. udviklingen i antallet af ældre i Danmark, 19802000. Working Paper, ÆIldrekommissionen 2. delrapport, De Ældres Vilkår, Copenhagen 1981.

- (1981). The elderly in Denmark in 1980: Consequences of a mortality decline. Euro. Dem. Inf. Bull., Vol. XII, 3: 89-100.

- (1982). Selvmord blandt de ældre i Danmark, Ugeskr. Læger, 144. 2965-8.

- and Matthiessen, P. C. (1982). The Aging of the Danish Population. In: Epidemiology and preventing of mental illness in old age, edited by G. Magnussen; J. Nielsen and J. Buch. Holbæk.

- (1984). Centenarians in Denmark. To be published by Akademiet for Fremtidsforskning. Copenhagen.

Matthiessen, P. C. and Leeson, G. W. (1983). Udviklingen i antallet af ældre i de nordiske lande fra 1960 til 2000. Icelandic Medical Jour. 16: 9-17.

Rosenwaike, I; Yaffe, M. and Sagi, P. C. (1980). The recent decline in mortality of the extreme aged. Am. J. Pub. Health 70 (10): 1074-1080. 